International Journal of Trend in Scientific Research and Development (IJTSRD)

Volume: 3 | Issue: 2 | Jan-Feb 2019 Available Online: www.ijtsrd.com e-ISSN: 2456 - 6470

\title{
Studies on Hybrid Material Reinforced Copper Based Composites- A Review
}

\author{
Goutham M1', Mahesh V M², Muralidhara B K ${ }^{3}$ \\ ${ }^{1}$ Research Scholar, ${ }^{2}$ Assistant Professor, ${ }^{3}$ Professor \\ 1,2Department of Mechanical Engineering, JSSSTU, Mysuru, Karnataka, India \\ 3Department of Mechanical Engineering, NMIT, Bengaluru, Karnataka, India
}

\begin{abstract}
Copper hybrid composites are a new generation of metal matrix composites that have the potentials of satisfying the recent demands of advanced engineering applications. These demands are met due to improved mechanical properties, amenability to conventional processing technique and possibility of reducing production cost of Copper hybrid composites. The performance of these materials is mostly dependent on selecting the right combination of reinforcing materials since some of the processing parameters are associated with the reinforcing particulates. This paper attempts to review the different reinforcing materials used in the processing of hybrid copper materials. The major procedures for fabricating these materials and research areas for further improvement on copper hybrid composites are suggested.
\end{abstract}

\section{KEYWORDS: Copper, composite, metal matrix, hybrid fibres}

\section{INTRODUCTION}

A composite material is made by combining two or more materials that have very different properties. The two materials work together to give the composite unique properties, within the composite, the different materials apart as they do not dissolve, blend into each other. The advantage of modern composite materials is that they are light as well as strong, choosing an appropriate combination of matrix and reinforcement material, a new material can be made that exactly meets the requirements of a particular application.

Based on the matrix material which forms the continuous phase, the composites are broadly classified into metal matrix (MMC), ceramic matrix (CMC) and polymer matrix (PMC) composites.

Polymer matrix composites are much easier to fabricate than MMC and CMC. This is due to the relatively low processing temperature required for fabricating polymer matrix composite. PMC's generally consist of synthetic fibers like carbon, nylon, rayon or glass embedded in a polymer matrix, which surrounds and tightly binds the fibers. Typically, the fibers make up about $60 \%$ of a polymer matrix composite by volume. The structure, properties and applications of various composites are being investigated worldwide by several researchers.

The fibrous reinforcing constituent of composites may consist of thin continuous fibers or relatively short fiber segments. When using short fiber segments, fibers with high aspect ratio (length to diameter ratio) are used. Continuous fiber reinforced composites are generally required for high performance structural applications. The specific strength and stiffness of continuous carbon fiber reinforced composites can be superior to conventional metal alloys. Also depending upon how fibers are oriented within the matrix, composites can be fabricated into products that have structural properties specifically tailored for a particular use. Polymer concretes are increasingly being used in buildings and other structures. They represent a new type of structural material capable of withstanding highly corrosive environments. The high strength to weight ratio and noncorrosive characteristics of these materials like fiberreinforced plastics can be utilised to build innovative structures, which are, desirable and economical.

\section{A. Types of composites}

1. iearticulate

2. Fiber

3. Laminate

4. Hybrid

A composite whose reinforcement is a particle with all the dimensions roughly equal are called particulate reinforced composites. Particulate fillers are employed to improve high temperature performance, reduce friction, increase wear resistance and to reduce shrinkage. The particles will also share the load with the matrix, but to a lesser extent than a fiber. A particulate reinforcement will therefore improve stiffness but will not generally strengthen.

Fiber reinforced composites contain reinforcements having lengths higher than cross sectional dimension. Fibrous reinforcement represents physical rather than a chemical means of changing a material to suit various engineering applications

Reinforcing fiber in a single layer composite may be short or long based on its overall dimensions. Composites with long fibers are called continuous fiber reinforcement and composite in which short or staple fibers are embedded in the matrix are termed as discontinuous fiber reinforcement. In continuous fiber composites fibers are oriented in one direction to produce enhanced strength properties. In short fiber composites, the length of short fiber is neither too high to allow individual fibers to mix with each other nor too small for the fibers to loss their fibrous nature. The reinforcement is uniform in the case of composites containing well dispersed short fibers. There is a clear 
distinction between the behaviour of short and long fiber composites.

Composite materials incorporated with two or more different types of fillers especially fibers in a single matrix are commonly known as hybrid composites. Hybridisation is commonly used for improving the properties and for lowering the cost of conventional composites. There are different types of hybrid composites classified according to the way in which the component materials are incorporated. Hybrids are designated as i) sandwich type ii) inter ply iii) intra ply and iv)intimately mixed.

A laminate is fabricated by stacking a number of laminae in the thickness direction. Generally three layers are arranged alternatively for better bonding between reinforcement and the polymer matrix, for example plywood and paper.

Laminates can have unidirectional or bi-directional orientation of the fiber reinforcement according to the end use of the composite. A hybrid laminate can also be fabricated by the use of different constituent materials or of the same material with different reinforcing pattern. In most of the applications of laminated composite, manmade fibers are used due to their good combination of physical, mechanical and thermal behaviour

\section{Metal matrix composites}

Metal matrix composites uses metal matrix dispersed with other metal, ceramic or organic compounds. Reinforcements are usually done to improve the various properties of the base metal. The particle distribution plays a very important role in the properties of MMCs. Copper, Magnesium and Aluminium has attracted more attention as base metal in metal matrix composites. These MMCs are widely used in aircraft, aerospace, automobiles, defence and various other fields. The most commonly used reinforcements are Silicon Carbide ( $\mathrm{SiC}$ ), TiO2, Aluminium Oxide ( $\mathrm{Al} 2 \mathrm{O} 3$ ), B4 C, Y2 O3, Si3 N4 , AlN. Al2 03 reinforcement shows good compressive strength and wear resistance.

Boron Carbide is one of hardest elements. It has high fracture toughness and elastic modulus. The addition of Boron Carbide (B4 C) in MMCs increases their hardness. Fibers play very important role as reinforcement, as they transfer strength to the matrix which results in the enhancement of their physical and mechanical properties as desired. Zircon is usually used in hybrid reinforcement for improving the wear resistance. In the last decade, lot of work has been done on fly ash reinforced MMCs. Due to their low cost and availability as waste by-product in thermal power plants. It improves the electromagnetic shielding effect of the MMCs. Based on the stated potential benefits of MMCs this paper investigates the affect of various dispersion on the mechanical properties of MMCs, processing methodology and their applications.

\section{LITERATURE REVIEW}

Madhusudan et al.[1], studied Mechanical properties of aluminium-copper(p) composite metallic materials. Composite metallic materials (CMMs) are prepared by dispersing copper particulates in aluminium matrix using stir-cast technique, its behaviour is compared with the alloy having similar composition. The effect of particulate composition is studied by varying the copper concentration between 5 and $15 \mathrm{wt} \%$. Hardness increased with increasing particulate contents in both cast and homogenized conditions, further increasing reinforcement content, the strength increased and dropped.

Shaaz abulai et al [2], studied the fabrication and characterization of copper matrix hybrid composites. Research emphasize the production of metal-matrix composites using the stir-casting fabrication method and preparing samples of varying percentage reinforcements (5\%, $10 \%$ and $15 \%$ by mass) of silicon carbide and aluminium oxide with copper. The major drawbacks of copper based composites are reduced conductivity and poor machinability. To overcome this, soft phase such as graphite as additional reinforcement was used. Graphite improves the machinability of the composites and also possess excellent thermal and electrical conductivity, thereby improving the conducting capability of copper composites.

Velugula et al[3]., Evaluated of mechanical characteristics for aluminium copper Metal matrix composite., The aluminiumcopper metal matrix composites are used in damage tolerance applications such as the lower wing skins and fuselage structure of commercial aircraft. In the present study, aluminium alloy specimens (6061) will be developed with variations of $\%$ of copper in the composition viz., $4 \%$, $6 \%, 8 \%, 10 \%$ using die casting process. It is observed from results that the hardness of $\mathrm{Al}$ alloy (6061) with $\mathrm{Cu}$ MMC increases with increasing wt $\%$ of copper particulate upto 8 $w t \%$ and then decreases with increasing wt $\%$ of copper particles. The tensile strength and impact strength of the composite increased with increase in wt\% of copper particulates up to $8 \%$.

P S Kori et al[4]., studied effect of copper coated SiC Reinforcements on microstructure, mechanical properties and wear of aluminium composites. Experimental results clearly revealed that, an addition of $\mathrm{SiC}$ particles $(5,10$ and $15 \mathrm{Wt} \%$ ) has lead in the improvement of hardness and ultimate tensile strength. Al-SiC composites containing the copper coated $\mathrm{SiC}$ reinforcements showed better improvement in mechanical properties compared to uncoated ones. Results suggested that, wear rate decreases with increasing $\mathrm{SiC}$ composition, further an improvement in wear resistance is observed with copper coated $\mathrm{SiC}$ reinforcements in the $\mathrm{Al}-\mathrm{SiC}$ metal matrix composites (MMC's).,

Harshpreet Singh et al.,[5] studied the development of $\mathrm{Cu}$ reinforced $\mathrm{SiC}$ particulate composites., $\mathrm{SiC}$ particles as reinforcement was blended with unmilled and as-milled $\mathrm{Cu}$ powder with reinforcement contents of 10, 20, 30, 40 vol. \% by powder metallurgy route. X-ray diffraction of all the composites was done in order to determine the various phases in the composites. Scanning electron microscopy (SEM) and EDS (electron diffraction x-ray spectroscopy) was carried out for the microstructural analysis of the composites. $\mathrm{Cu}-\mathrm{SiC}$ composites containing higher vol. \% of the $\mathrm{SiC}$ shows better wear resistance. All the $\mathrm{Cu}-\mathrm{SiC}$ composites developed show better wear resistance than pure $\mathrm{Cu}$.

Manvandra Kumar Singh [6], studied the mechanical property of dual reinforced copper based hybrid composite. The main objective is to fabricate a copper based metal matrix hybrid composite using stir casting technique for better mechanical properties than its matrix materials to 
fulfill this requisite mechanical property of hybrid composite, the addition of two hard ceramic materials liketungsten carbide and zirconium oxide ( $\mathrm{ZrO} 2$ ) is used as reinforcement in a definite amount into the copper matrix. The developed hybrid composites are further characterized by optical microscope, scanning electron microscope (SEM) and hardness test. These characterizations assure that the developed material is hybrid because matrix is containing both the reinforcements. However, hardness of the copper based hybrid composite materials is higher than the commercial copper matrix.

R.Noor Ahmed et al[7] evaluated tribological properties of cast copper-SiC-graphite hybrid composites. Cast Copper $\mathrm{SiC}$ graphite Composites have been developed successfully by liquid metallurgy route. The hard reinforcement $\mathrm{SiC}$ of 3,5 \& $10 \mathrm{wt} \%$ has been dispersed along with soft reinforcement graphite of $1 \mathrm{wt} \%$ in high purity copper scrap. The cast $\mathrm{Cu}$ SiC-Graphite composites have been subjected to micro hardness, friction \& wear tests. Metallography studies have revealed uniformity in distribution of reinforcement in the matrix metal. Increased content of $\mathrm{SiC}$ in the hybrid composite has resulted in better wear resistance of the hybrid composites. Presence of graphite in the hybrid composite has resulted in lowering of coefficient of friction of hybrid composites when compared with $\mathrm{Cu}-\mathrm{SiC}$ composites.

T Ram prabhu [8].,studied Processing and study of the wear and friction behaviour of discrete graded $\mathrm{Cu}$ hybrid composites, discrete functional graded $\mathrm{Cu} / 10 \% \mathrm{SiC} /$ 20\%graphite(Gr)/10\%boron nitride hybrid composites were prepared by the layer stacking compaction and pressure sintering techniques. The mechanical properties (flexural strength and surface hardness) of composites are not affected by the particle size, the incorporation of copper layer in the discrete layer structure deflects and arrests the crack at the copper/composite layer interface, thus improving the fracture resistance in addition to improving the bulk thermal conductivity.

Mohsen Barmouz et al[9], studied mechanical and microstructural characterization of hybrid $\mathrm{Cu}-\mathrm{SiC}-\mathrm{Zn}$ composites fabricated via friction stir processing, an attempt has been made to fabricate hybrid $\mathrm{Cu}-\mathrm{SiC}-\mathrm{Zn}$ composites by friction stir processing technique. Through this investigation the different number of passes was applied to assess the effect of pass adding on the mechanical, microstructural and dislocation density behaviour of the specimens. According to the obtained results, the higher passes led to obtain more uniform dispersion of the SiC particles and intermetallic phases. The calculated values for the dislocation densities showed that presence of $\mathrm{SiC}$ particles and inter metallic phases could rise up the dislocation values. Measured micro hardness values for the composites exhibit that they enhanced rather than base metal and these results were confirmed by dislocation densities values of the specimens.

R. K. Khatitrkar et al.,[10] studied the abrasive wear behaviour of $\mathrm{Cu}-\mathrm{SiC}$ and $\mathrm{Cu}-\mathrm{SiO} 2$ composites. $\mathrm{Cu} \mathrm{SiC}(12 \%)$ and Copper-SiO2 (9\%) composites were prepared by powder metallurgical technique. The abrasive wear experiments were carried out using pin on disc apparatus. The effect of sliding distance and load was studied on $\mathrm{Cu} \mathrm{SiC}$ (12\%) and Copper-SiO2 (9\%) composites. The abrasive wear volume loss increased with sliding distance in both the composites although the magnitude of increase was different in each case. $\mathrm{Cu} \mathrm{SiC}(12 \%)$ composites exhibited relatively better abrasion resistance as compared to and $\mathrm{Cu} \mathrm{SiO2} \mathrm{(9 \% )}$ composites.

H. M. Mallikarjuna et al., [11] studied microstructure and micro hardness of carbon nanotube-silicon carbide/copper hybrid nanocomposite developed by powder metallurgy. Hybrid nanocomposites have been synthesised by powder metallurgy technique which involves blending of composite powder, compaction, sintering followed by hot pressing. The densities of nanocomposites were significantly reduced owing to low densities of MWCNTs and SiC. An improvement in hardness of about 1.5 times has been observed for nano composites when compared with pure copper prepared under similar conditions. However, reduction in electrical conductivity of nano composites was observed due to grain refinement caused by multiple reinforcements.

\section{CONCLUSION}

From the above literature review most of the applications were made by hybrid composites materials, so it can reduce the cost and improve the strength and desirable properties for different usages, hybrid composite is an emerging field in all industries because of its benefits of high strength to weight ratio

\section{REFERENCES}

[1] Siddabathula Madhusudan a,Mohammed Moulana Mohiuddin Sarcar b, Narsipalli Bhargava Rama Mohan Rao., Mechanical properties of Aluminium-Copper(p) composite metallic materials., Journal of Applied Research and Technology 293-299,Vol 14, 2016

[2] Shaaz abulais, vikrant yadav, aniruddha muley., fabrication and characterization of copper matrix hybrid composite., International Journal of Mechanical And Production Engineering, ISSN: 2320-2092

[3] Velugula Mani Kumar and Chinta Neelima Devi., Evaluation of mechanical characteristics for Aluminium-copper Metal matrix composite., Research Journal of Engineering Sciences Vol. 3(3), 1-5, March (2014)

[4] P S Kori, Mohan Vanarotti, B M.Angadi, V V Nagathan, V Auradi , M I Sakri., Effect of Copper Coated SiC Reinforcements on Microstructure, Mechanical Properties and Wear of Aluminium Composites., IOP Conf. Series: Materials Science and Engineering 225, 2017

[5] Harshpreet Singh, Lailesh Kumar, Syed Nasimul Alam., Development of $\mathrm{Cu}$ Reinforced SiC Particulate Composites., IOP Conf. Ser.: Mater. Sci. Eng. 75012007

[6] Manvandra Kumar Singh, Mechanical property of dual reinforced copper based hybrid composite., Conference: National Conference on Product Design and Manufacturing (NCPDM-2015), At Mechanical Engineering Department Motilal Nehru National Institute of Technology Allahabad.

[7] R. Noor Ahmed and C. S. Ramesh., tribological properties of cast copper-SiC-graphite hybrid composites, International Symposium of Research Students on Materials Science and Engineering December 20-22, 2004, 
[8] T RAM PRABHU., Processing and study of the wear and friction behaviour of discrete graded $\mathrm{Cu}$ hybrid composites, Bull. Mater. Sci., Vol. 38, No. 3, pp. 753760, June 2015

[9] Mohsen Barmouz Vahid Zal., Hamed Pashazadeh., Mechanical and Microstructural Characterization of Hybrid $\mathrm{Cu}-\mathrm{SiC}-\mathrm{Zn}$ Composites Fabricated Via Friction Stir Processing., Mat. Res. vol.19 no.6 São Carlos Nov./Dec. 2016

[10] R. K. Khatitrkar, s. G. Sapate., abrasive wear behaviour of copper-SiC and copper-sio2 composites.,
International Journal of Modern PhySiCs: Conference Series Vol. 22 (416-423), 2013

[11] H. M. Mallikarjuna, C. S. Ramesh, Praveennath G. Koppad, K. T. Kashyap, R. Keshavamurthy., Microstructure and Microhardness of Carbon Nanotube-Silicon Carbide/Copper Hybrid Nanocomposite Developed by Powder Metallurgy., Indian Journal of Science and Technology, Vol 9(14), DOI: 10.17485/ijst/2016/v9i14/84063, April 2016

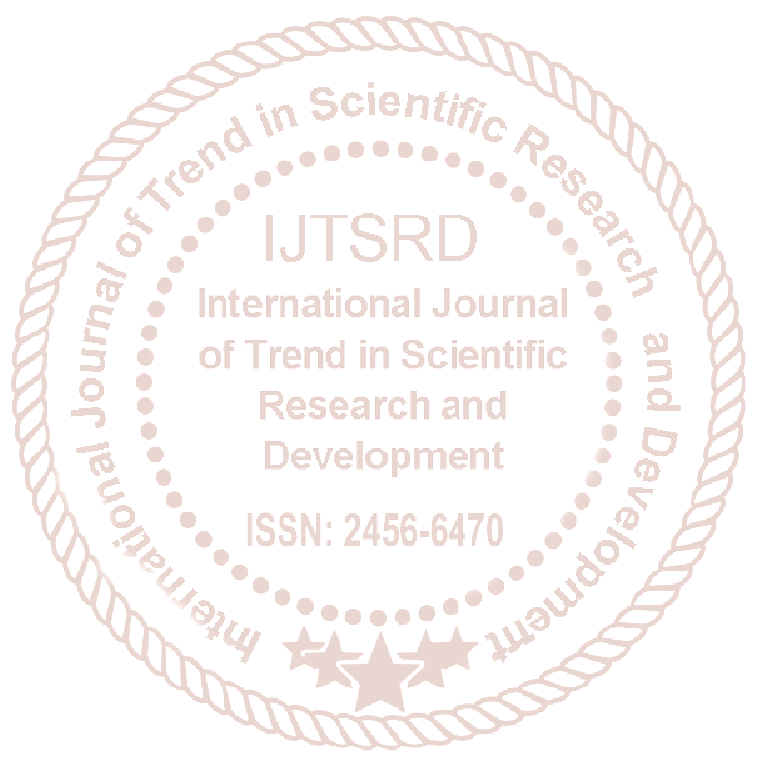

